\title{
Wnt/ $\beta$-catenin inhibition reverses multidrug resistance in pediatric acute lymphoblastic leukemia
}

\author{
JINQIU FU ${ }^{1 *}$, LIBO SI $^{2 *}$, YONG ZHUANG ${ }^{1}$, AIJUN ZHANG $^{1}$, \\ NIANZHENG SUN ${ }^{1}$, DONG LI ${ }^{1}$, BIN HAO $^{3}$ and XIULI JU ${ }^{1}$ \\ Departments of ${ }^{1}$ Pediatrics and ${ }^{2}$ Thoracic Surgery, Qilu Hospital, Shandong University, Jinan, Shandong 250012; \\ ${ }^{3}$ Department of Cardiothoracic Surgery, Zibo Central Hospital, Zibo, Shandong 255036, P.R. China
}

Received July 31, 2018; Accepted November 22, 2018

DOI: $10.3892 /$ or.2018.6902

\begin{abstract}
Although $~ 80 \%$ of newly diagnosed pediatric patients with acute lymphoblastic leukemia (ALL) become disease-free following appropriate treatment, relapses frequently occur, with dismal prognosis. Therefore, it is urgent to develop novel therapeutic modalities. Resistance to chemotherapy is a major obstacle for the treatment of relapsed ALL. It has been indicated that Wnt pathway is potentially associated with leukemia recurrence. In the current study, a vincristine (VCR)-resistant variant of the human ALL cell line BALL-1 (BALL-1/VCR) that also had relatively specific resistance to both doxorubicin and etoposide was generated. Over-activation of the Wnt/ $\beta$-catenin signaling pathway was observed in BALL-1/VCR cells, whereas Dickkopf-related protein 1 selectively suppressed the Wnt signaling pathway and sensitized the response of BALL-1/VCR to anticancer agents. In addition, prednisolone exposure in combination with Wnt inhibition restored chemo-sensitivity in relapsed ALL blasts. Since the resistance of BALL-1/VCR cells is potentially attributed to the overexpression of MDR-associated protein 1 (MRP1), the development of drug resistance in relapsed ALL may associated with the overexpression of MRP1 and P-glycoprotein. The results of this study demonstrated that, as a potential candidate to mimic relapsed ALL, BALL-1/VCR could be used in further research, while Wnt-inhibition may become a promising therapeutic approach for treating ALL.
\end{abstract}

\section{Introduction}

Acute lymphoblastic leukemia (ALL) is a rapidly progressing disease characterized by the progressive accumulation of immature clonal cells in the bone marrow (BM). The molecular

Correspondence to: Professor Xiuli Ju, Department of Pediatrics, Qilu Hospital, Shandong University, 107 West of Wenhua Road, Jinan, Shandong 250012, P.R. China

E-mail: jxlqlyy@163.com

${ }^{*}$ Contributed equally

Key words: acute lymphoblastic leukemia, relapse, resistance, Wnt/ $\beta$-catenin inhibition pathogenesis of ALL involves the aberrant expression of protooncogenes in several signaling pathways, chromosomal translocations of transcription factors and hyperdiploidy (1). Currently, $\sim 80 \%$ of all newly diagnosed pediatric patients with ALL can become disease-free following adequate treatment; however, a small number of children still experience ALL relapse (2). Treatment of relapsed ALL is largely ineffective, as the response rate to chemotherapeutic drugs is only $10-20 \%$, which is often attributed to the effect of ATP-binding cassette (ABC) transporter family members, multidrug resistance 1 (MDR1) and MDR-associated protein (MRP) $(3,4)$. The mechanisms of drug resistance are associated with the overexpression of drug-efflux pumps, including MDR1-encoded and membrane-located P-glycoprotein (P-gp) and MRP. The overexpression of drug-efflux pumps promotes the cellular escape of anticancer drugs, especially natural drugs and anthracyclines, including vinca alkaloids, vinblastine, vincristine (5) and doxorubicin. Therefore, it is urgent to develop novel therapeutic strategies to increase sensitivity of ALL to chemotherapeutic drugs.

The canonical Wnt/ $\beta$-catenin signaling pathway is an evolutionarily conserved cascade that controls a variety of cellular activities, including cell proliferation, migration, apoptosis and gene expression during embryonic development. Previous studies have investigated the abnormal expression of Wnt/ $\beta$-catenin signaling pathway in solid cancer (6) and hematologic malignancies (7), including acute myeloid leukemia (AML) and ALL. It has been indicated that MDR1 is activated by the Wnt/ $\beta$-catenin signaling pathway, potentially leading to chemoresistance (8).

Because resistance to chemotherapy is a major obstacle in successful treatment of relapsed ALL, it is hypothesized that modulation of the Wnt/ $\beta$-catenin signaling may affect the expression of MDR1, and improve the sensitivity to chemotherapeutic drugs. In the current study, a novel variant of BALL-1, the B cell lineage of an ALL cell line, was selected to mimic relapsed ALL. The new BALL-1 variant was resistant to vincristine (VCR), an essential component in childhood ALL therapies. In addition, multidrug resistance and increased levels of several critical proteins in the Wnt/ $\beta$-catenin signaling pathway were identified in passaged BALL-1/VCR cells, consistent with those of relapsed ALL. Subsequently, Dickkopf-related protein 1 (DKK1) was used to inhibit the Wnt/ $\beta$-catenin signaling pathway, and to abolish the resistance in BALL-1/VCR and relapsed ALL cells. 
Finally, the potential mechanism of drug resistance involving MDR1 and MRP was explored in the present study.

\section{Materials and methods}

Patient samples. Bone marrow samples from patients at first diagnosis of ALL and relapsed ALL were collected at and provided by Shandong University Qilu Hospital (Jinan, China). The primary cells were separated from bone marrow by Ficoll-Hypaque centrifugation and maintained in a fresh culture medium (RPMI-1640; Thermo Fisher Scientific, Inc., Waltham, MA, USA) containing $20 \%$ fetal bovine serum (FBS; Thermo Fisher Scientific, Inc.) and 1\% penicillin-streptomycin. Informed consent was obtained from all patients or their guardians. The protocol followed the Declaration of Helsinki and was approved by Ethic Committee in Qilu Hospital of Shandong University (no. KYLL-2017-253).

Materials. RPMI-1640 and FBS were obtained from Gibco (Thermo Fisher Scientific, Inc.). Vincristine, vindesine (VDS), doxorubicin, etoposide (VP16), mitoxantrone, cisplatin, camptothecin (Sigma-Aldrich; Merck KGaA, Darmstadt, Germany), and prednisolone (Shandong Xinhua Pharmaceutical Co., Ltd., Zibo, China) were serially diluted in RPMI and added to the culture media at the indicated concentrations.

Cell lines. Wild-type BALL-1 (BALL-1/WT) and VCR-resistant BALL-1 (BALL-1/VCR) human ALL cells were cultured at $37^{\circ} \mathrm{C}$ in $5 \% \mathrm{CO}_{2}$ in RPMI-1640 containing $10 \% \mathrm{FBS}$. The wild-type BALL-1 cell line without mycoplasma contamination were donated by Professor Dao-xin Ma (Key Laboratory of Shandong Province, Shandong University Qilu Hospital, Jinan, China). The VCR-resistant variants of BALL-1/WT cells were isolated by stepwise selection using increasing concentrations of VCR, which started from $2 \mathrm{X} \mathrm{IC}_{50}(970 \mathrm{M})$. When cells became confluent in the VCR containing medium, the drug concentration was increased to $3 \mathrm{X}(1,455 \mathrm{M}), 5 \mathrm{X}(2,425 \mathrm{M}), 10 \mathrm{X}(4,850 \mathrm{M})$, 20X $(9,700 \mathrm{M}), 30 \mathrm{X}(14,550 \mathrm{M}), 50 \mathrm{X}(24,250 \mathrm{M})$ and $100 \mathrm{X} \mathrm{IC}$ $(48,450 \mathrm{M})$, which was the maximal concentration. Following the selection of BALL-1/VCR cells, they were sub-cultured in a medium containing $6062.5 \mathrm{M}$ VCR and were stably resistant to VCR for several months.

DKK1-conditioned medium (DKK1-CM). 293T cells (donated by Tnstitute of Immunology, Shandong University, Jinan, China) were cultured in Dulbecco's modified Eagle's medium-conditioned medium (Biochrom, Ltd., Cambridge, UK) containing 10\% FBS (HyClone; GE Healthcare Life Sciences, Logan, UT, USA) and $1 \times 10^{6}$ cells were transfected with $3 \mu \mathrm{g}$ pcDNA3.1-DKK1 [designed and synthesized by Shanghai GenePharma Co., Ltd. (Shanghai, China)] using Lipofectamine ${ }^{\circledR} 2000$ (Invitrogen; Thermo Fisher Scientific, Inc.). The supernatant was collected as the DKK1-conditioned media $48 \mathrm{~h}$ later and stored at $-70^{\circ} \mathrm{C}$ for subsequent experiments.

To inhibit the canonical Wnt signaling pathway, BALL-1/VCR cells were seeded onto a 24-well plate at a density of $2 \times 10^{4}$ cells/well and treated with $1 \mathrm{ml}$ DKK1-CM for $48 \mathrm{~h}$.

Cytotoxicity assays. The effect of anticancer agents on cell viability was assessed using MTT assay as described previously (9). In brief, cells (4-5x $10^{3}$ per well) were seeded in 96-well plates and incubated for $24 \mathrm{~h}$ at $37^{\circ} \mathrm{C}$. Subsequently, the cells were exposed to varying concentrations of anticancer drugs for a specific time before treated by $20 \mu \mathrm{l} /$ well MTT $(5 \mathrm{mg} / \mathrm{ml}$ ) for $4 \mathrm{~h}$. Subsequently, dimethyl sulfoxide (DMSO) was added to treat the cells for $10 \mathrm{~min}$ and the optical density in each well was measured using a microplate reader (Bio-Rad 450; Bio-Rad Laboratories, Inc., Rantoul, IL, USA) at $570 \mathrm{~nm}$. The cell viability ratio (\%) was calculated based on the formula below: (A570 sample-A570 blank)/(A570 control-A570 blank) x 100 . The $\mathrm{IC}_{50}$ value of the cells was deemed as the drug dose that caused $50 \%$ of absorbance reduction compared with DMSO-treated control cells. Each experiment was performed in triplicate independently.

Reverse transcription-quantitative polymerase chain reaction (RT-qPCR). In brief, total RNA was isolated from cells using TRIzol (Invitrogen; Thermo Fisher Scientific, Inc.) and RT was performed using Quant reverse transcriptase (Beyotime Institute of Biotechnology, Haimen, China) with incubation at $42^{\circ} \mathrm{C}$ for $30 \mathrm{~min}$ and $85^{\circ} \mathrm{C}$ for $5 \mathrm{~min}$. The sequences of the primers are listed in Table I. qPCR was performed using RealMasterMix (SYBR Green; Beyotime Institute of Biotechnology) for 30 cycles of amplification $\left(95^{\circ} \mathrm{C}\right.$ for $10 \mathrm{~min}$ followed by 30 cycles of $95^{\circ} \mathrm{C}$ for $15 \mathrm{sec}$ and $62^{\circ} \mathrm{C}$ for $1 \mathrm{~min}$ ). The gene expression was quantified using the comparative $2^{-\Delta \Delta \mathrm{Cq}}(10)$ method and then normalized to the expression of GAPDH (11).

Flow cytometry. Apoptosis was evaluated by flow cytometry using Annexin V/propidium iodide (PI) double staining (Invitrogen; Thermo Fisher Scientific, Inc.). The analysis was performed using a Guava EasyCyte 8HT flow cytometer (EMD Millipore, Billerica, MA, USA) for a total of 50,000 counts. The results were analyzed using guavaSoft 3.1.1 (Merck KGaA).

Western blot analysis. The cells were lysed on ice in radioimmunoprecipitation assay (RIPA) lysis buffer inhibitor cocktail (Roche Applied Science, Mannheim, Germany) for $30 \mathrm{~min}$. After adding isopropanol on ice and melting at $37^{\circ} \mathrm{C}$ for three times, lysate was boiled at $100^{\circ} \mathrm{C}$ for $5 \mathrm{~min}$ and centrifuged at $16,750 \mathrm{xg}$ for $10 \mathrm{~min}$, and supernatant containing nuclear protein was collected. The protein concentrations were detected using a bicinchoninic acid protein assay kit (Beyotime Institute of Biotechnology). For total proteins, the cells were lysed on ice in RIPA lysis buffer inhibitor cocktail (Roche Applied Science) for $30 \mathrm{~min}$. After 13,400 x g centrifugation for $10 \mathrm{~min}$, the supernatant containing total protein was collected. Equal amounts of protein or nuclear protein $(60 \mathrm{mg})$ from each sample were separated by SDS-PAGE on $12 \%$ gels and transferred onto polyvinylidene difluoride membranes (EMD Millipore), which were immunoblotted overnight at $4{ }^{\circ} \mathrm{C}$ with primary antibodies against $\beta$-catenin (cat. no. ab16051; Abcam, Cambridge, UK; 1:1,000), lymphoid enhancer binding factor 1 (LEF1; cat. no. MA5-14966; Thermo Fisher Scientific, Inc.; 1:1,000) and GAPDH (cat. no. ab9485; Abcam; 1:1,000). Following washing three times (5 min each time), the membranes were incubated with horseradish peroxidase-conjugated secondary antibody (cat. no. TA130005; OriGene Technologies, Inc., Beijing, China; 1:4,000) at room 
Table I. Primer information.

\begin{tabular}{lll}
\hline Gene & \multicolumn{1}{c}{ Forward sequence $\left(5^{\prime}-3^{\prime}\right)$} & \multicolumn{1}{c}{ Reverse sequence $\left(5^{\prime}-3^{\prime}\right)$} \\
\hline Wnt3a & CTTTGCAGTGACACGCTCAT & GTGCTTCTCCACCACCATCT \\
Wnt5b & CCAACTCCTGGTGGTCATTAGC & TGGGCACCGATGATAAACATC \\
Wnt10a & CTGGGTGCTCCTGTTCTTCCTA & GAGGCGGAGGTCCAGAATG \\
Wnt14 & GGGCAGACGGTCAAGCAA & CCAGCCTTGATCACCTTCACA \\
Wnt16 & GCCAATTTGCCGCTGAAC & CGGCAGCAGGTACGGTTT \\
Fzd3 & TGGCTATGGTGGATGATCAAAG & TGGAGGCTGCCGTGGTA \\
Fzd6 & ACAAGCTGAAGGTCATTTCCAAA & GCTACTGCAGAAGTGCCATGAT \\
LRP6 & CGTGATTGCCGACGATCTC & TCCGGCCGCTAGTCTTGTC \\
GAPDH & TTATGTGCCACACCCAAGTTCT & CTGAGGGAGCTGATCATTGATTTA \\
\hline
\end{tabular}

Fzd, frizzled; LRP, LDL receptor related protein.

Table II. Sensitivity of BALL-1/WT and BALL-1/VCR cells to various anticancer agents.

\begin{tabular}{lrcc}
\hline & \multicolumn{2}{c}{$\mathrm{IC50}(\mu \mathrm{M})$} & \\
\cline { 2 - 3 } Drug & BALL-1/WT & BALL-1/VCR & Fold change \\
\hline Vincristine & $514 \pm 30.8$ & $12,858 \pm 1144$ & 25 \\
Vindesine & $446 \pm 28.9$ & $9,799 \pm 140$ & 22 \\
Doxorubicin & $5.57 \pm 0.57$ & $53.62 \pm 6.38$ & 9.6 \\
VP16 & $0.92 \pm 0.10$ & $4.60 \pm 0.32$ & 5 \\
Mitoxantrone & $1.10 \pm 0.07$ & $3.55 \pm 0.25$ & 3.2 \\
Cisplatin & $5.03 \pm 0.47$ & $12.03 \pm 0.07$ & 2.4 \\
Camptothecin & $12.43 \pm 1.75$ & $15.59 \pm 2.01$ & 1.3
\end{tabular}

The data are expressed as the IC50 $(\mu \mathrm{M}) \pm$ standard deviation. WT, wild-type; VCR, vincristine; VP16, etoposide.

temperature for $1 \mathrm{~h}$, subsequently washed and visualized using enhanced chemiluminescence (EMD Millipore).

Statistical analysis. Data are expressed as the mean \pm standard deviation. Flow cytometry results were analyzed using guavaSoft 3.1.1 (Merck KGaA). All statistical analyses were performed by two-way analysis of variance followed by Bonferroni's multiple comparison test. All statistical analyses were conducted using the GraphPad Prism 5 (GraphPad Software, Inc., La Jolla, CA, USA).

\section{Results}

BALL-1/VCR cells displayed multidrug resistance. The vincristine-resistant BALL-1 ALL cell line (BALL-1/VCR) was established by stepwise selection in increasing concentrations of vincristine. As presented in Table II, the resistance of BALL-1/VCR cells to vincristine and VDS was 25- and 22-fold of that in BALL-1/WT cells, respectively. In addition, the resistance of the BALL-1/VCR cell line to doxorubicin and VP16 was 9- and 5-fold of BALL-1/WT cells, respectively.
Table III. mRNA expression profile of Wnt family members in BALL-1/WT and BALL-1/VCR cells.

\begin{tabular}{lrcc}
\hline Gene & BALL-1/WT & BALL-1/VCR & P-value \\
\hline Wnt3a & $15.03 \pm 2.28$ & $25.36 \pm 2.28$ & $<0.01$ \\
Wnt5b & $11.09 \pm 2.60$ & $17.93 \pm 2.81$ & $<0.01$ \\
Wnt10a & $9.86 \pm 1.66$ & $16.08 \pm 2.31$ & $<0.01$ \\
Wnt14 & $9.67 \pm 3.02$ & $15.91 \pm 3.36$ & $<0.01$ \\
Wnt16 & $12.99 \pm 3.21$ & $23.02 \pm 4.37$ & $<0.01$ \\
Fzd3 & $9.59 \pm 2.43$ & $13.80 \pm 3.51$ & $<0.01$ \\
Fzd6 & $12.09 \pm 2.28$ & $17.63 \pm 3.62$ & $<0.01$ \\
LRP5 & $14.00 \pm 2.60$ & $25.03 \pm 4.32$ & $<0.01$ \\
LRP6 & $9.47 \pm 3.46$ & $17.84 \pm 3.60$ & $<0.01$ \\
\hline
\end{tabular}

The data are expressed as the mean \pm standard deviation. WT, wild-type; VCR, vincristine; Fzd, frizzled; LRP, LDL receptor related protein.

However, these cells exhibited little cross-resistance $(<4$-fold resistance) to other drugs including mitoxantrone, camptothecin and cisplatin.

Activated Wnt/ $\beta$-catenin signaling pathway in BALL-1/VCR cells. Expression levels of several Wnt family members and their downstream signaling components were measured in BALL-1/WT and BALL-1/VCR cells using RT-qPCR. The transcripts of Wnt family members were expressed in both cell lines. However, in BALL-1/VCR cells, levels of Wnt3a, Wnt5b, Wnt10a, Wnt14, Wnt16, Frizzled (Fzd)3, Fzd6, LDL receptor related protein (LRP)5 and LRP6 were significantly higher (Table III). In addition, the expression of Wnt3a, Wnt16 and LRP5 were the highest (Fig. 1A).

The canonical Wnt signaling pathway is activated by the accumulation and nuclear translocation of $\beta$-catenin, which binds to the transcription factors in the LEF/T-cell factor (TCF) family. The expression of nuclear $\beta$-catenin and LEF1 was increased significantly in BALL-1/VCR cells compared with that in BALL-1/WT cells (Fig. 1B). 

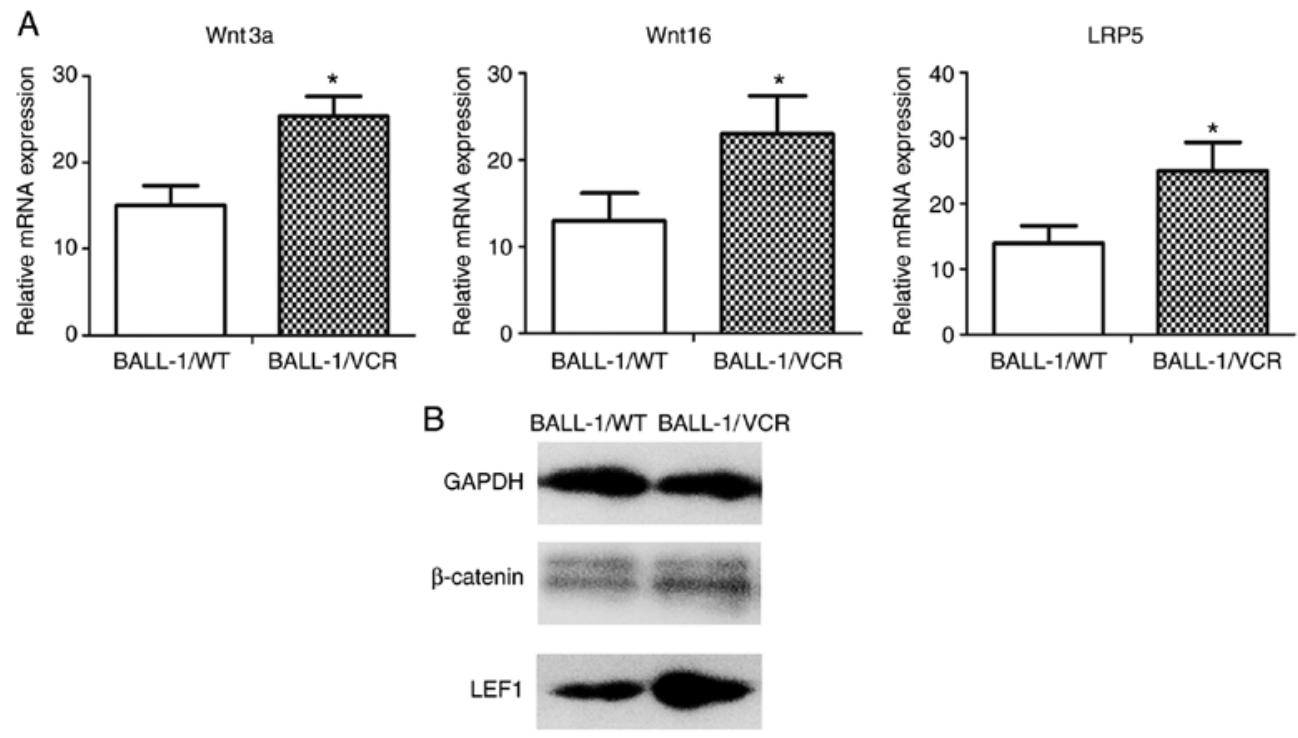

Figure 1. Activated Wnt/ $\beta$-catenin signaling pathway in BALL-1/VCR cells. (A) The relative mRNA expression of Wnt3a, Wnt16 and LRP5 in BALL-1/WT and BALL-1/VCR cells determined by reverse transcription-polymerase chain reaction. Each experiment was performed in triplicate. The data are expressed as the mean \pm standard deviation. ${ }^{*} \mathrm{P}<0.01 \mathrm{vs.} \mathrm{BALL-1/WT}$. (B) The expression levels of nuclear $\beta$-catenin and LEF1 protein in BALL-1/WT and BALL-1/VCR cells determined by western blot analysis. WT, wild-type; VCR, vincristine; LRP, LDL receptor related protein; LEF1, lymphoid enhancer binding factor 1.
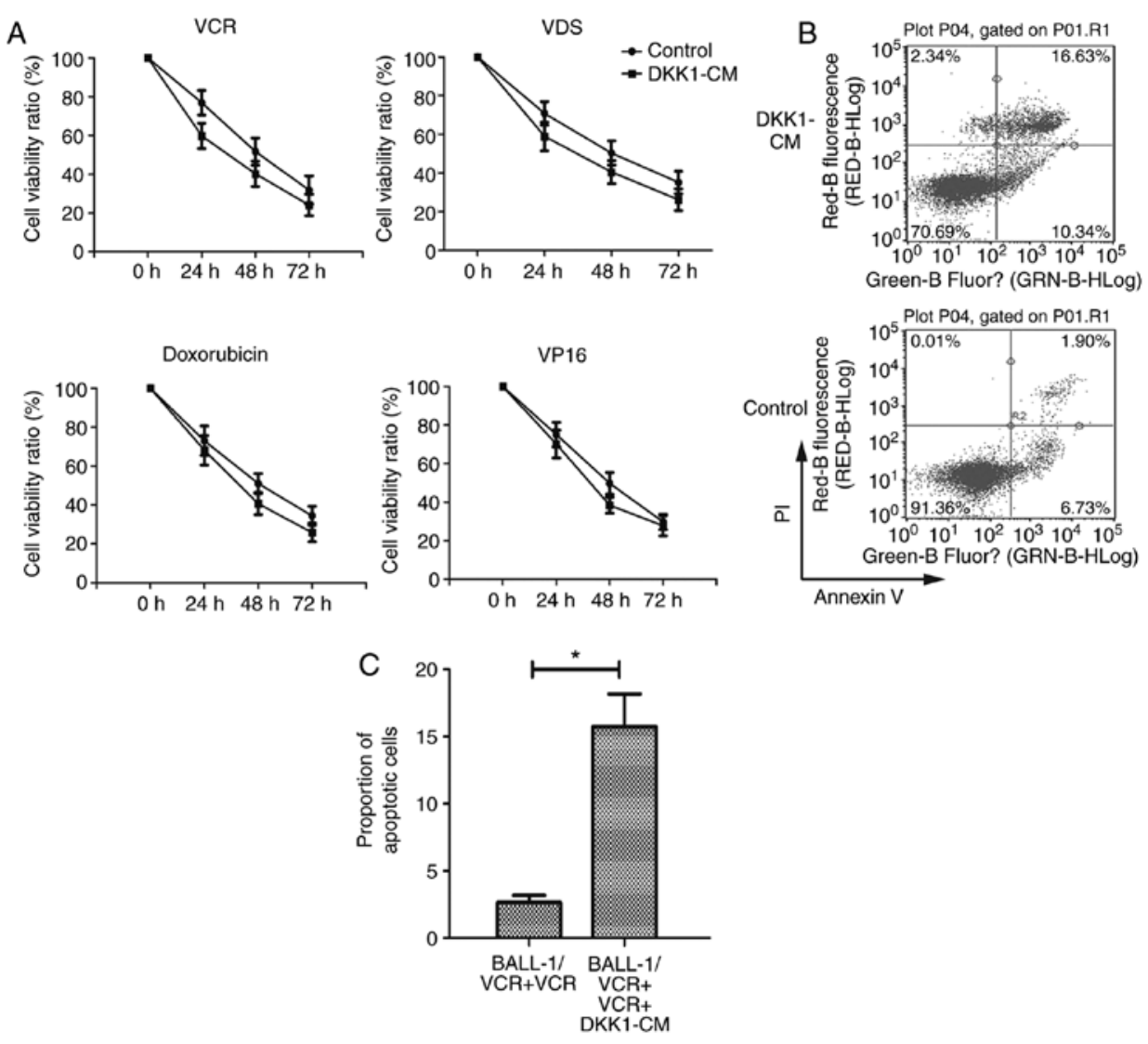

Figure 2. Increased chemosensitivity in BALL-1/VCR cells by Wnt inhibitor DKK1. (A) BALL-1/VCR cells were treated with DKK1-CM for $48 \mathrm{~h}$ before adding VCR $(12,125 \mathrm{M})$, VDS (9,390 M), Doxorubicin (53 M) and VP16 (5 M). Cell viability was assessed at 0,24, 48 and $72 \mathrm{~h}$ by MTT assay. The data are expressed as the mean \pm standard deviation (\% cell viability) of triplicate experiments. (B) BALL-1/VCR cells were exposed to DKK1-CM for $48 \mathrm{~h}$. (B) Representative plots of $12 \mathrm{~h}$ cultures in the presence of VCR $(12,125 \mathrm{M})$. (C) The apoptosis of cells was quantified using Annexin V and PI labeling and flow cytometry analysis. ${ }^{\text {"P}} \mathrm{P}$ 0.01. VCR, vincristine; VDS, vindesine; DKK1, Dickkopf-related protein 1; VP16, etoposide; CM, conditioned media; PI, propidium iodide.

Increased chemo-sensitivity of BALL-1/VCR cells treated with DKK1-CM. Subsequently, the Wnt/ $\beta$-catenin signaling pathway in BALL-1/VCR cells was inhibited by DKK1-CM.
To assess the drug sensitivity of BALL-1/VCR cells, the cells were treated with anticancer drugs prior to and following the DKK1-CM treatment. As presented in Fig. 2A, the cells 


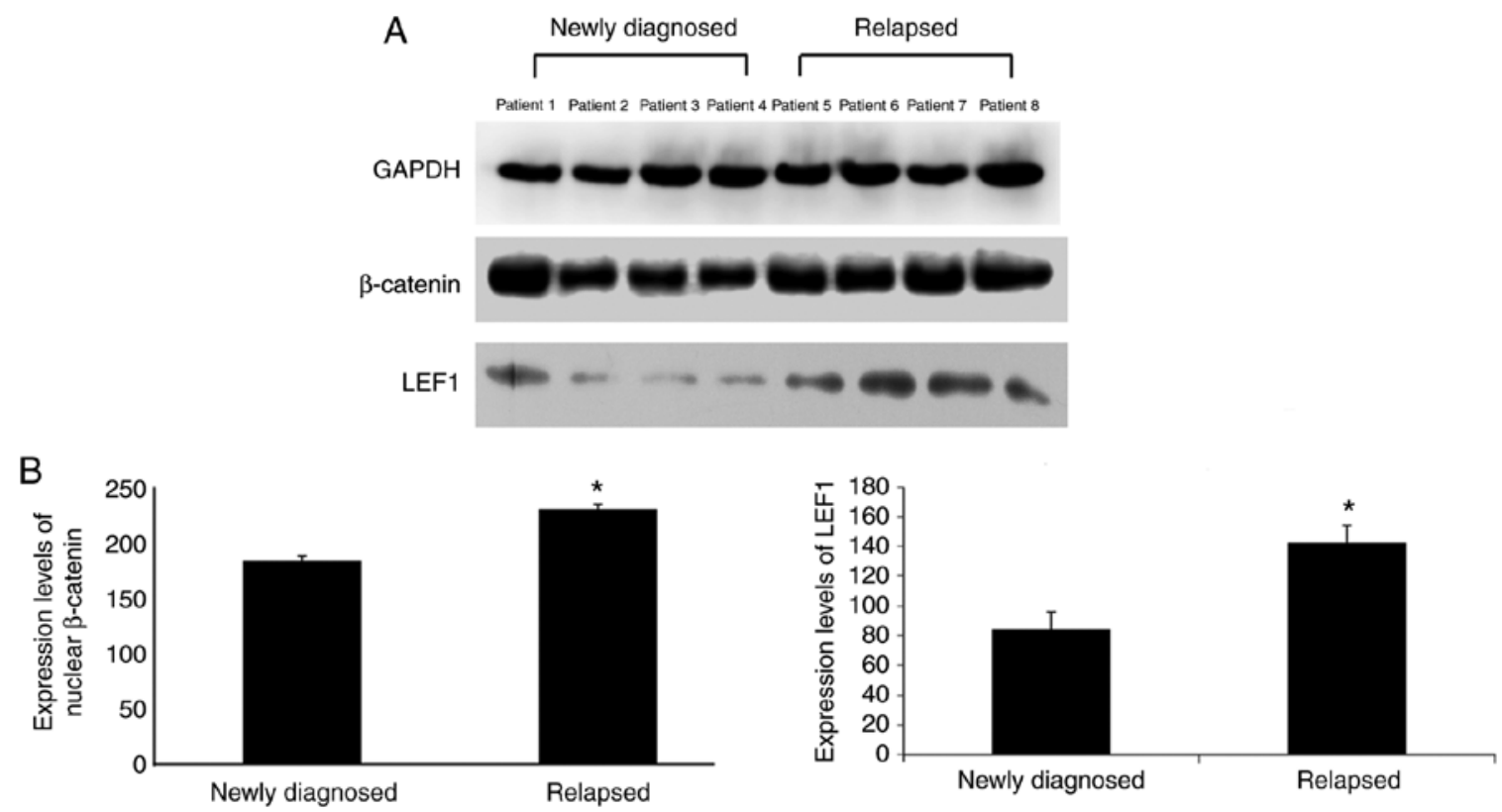

Figure 3. (A) Expression levels of nuclear $\beta$-catenin and LEF1 in newly diagnosed and relapsed acute lymphoid leukemia blasts determined by western blot analysis. (B) The gray value for nuclear $\beta$-catenin and LEF1. "P<0.01. LEF1, lymphoid enhancer binding factor 1 .
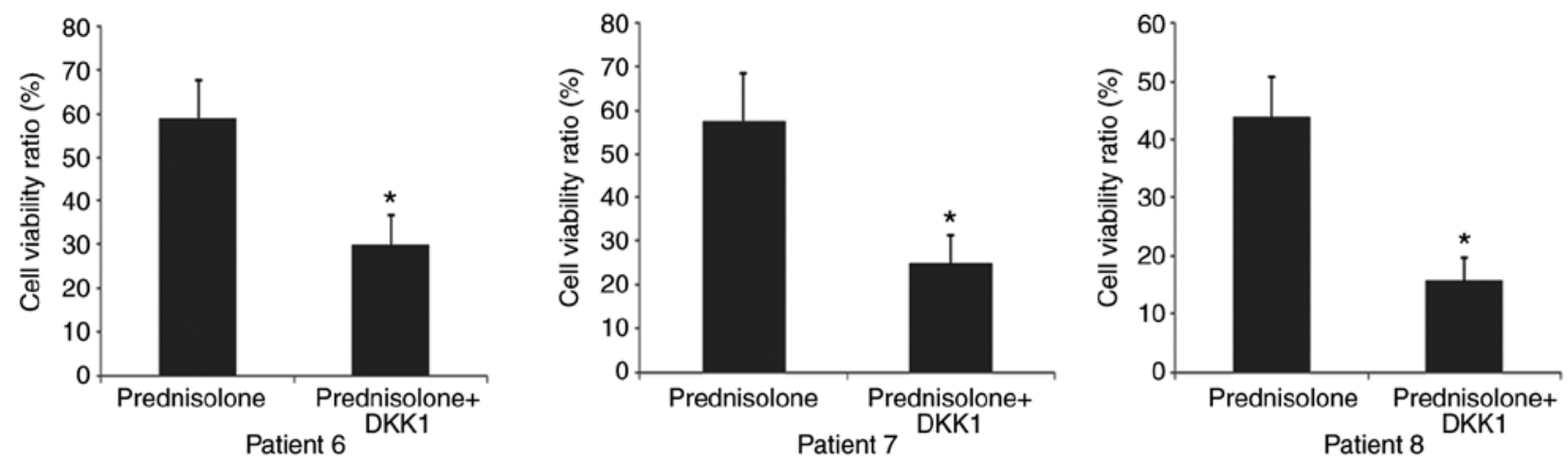

Figure 4. Increased chemosensitivity in relapsed leukemic cells to prednisolone by Wnt inhibitor DKK1. Cell viability assays were performed on blast cells derived from relapse patients (patient 6,7 and 8), which were treated with prednisolone $(200 \mu \mathrm{g} / \mathrm{ml})$ for $48 \mathrm{~h}$ and pretreated with or without DKK1-conditioned media for $48 \mathrm{~h}$. The data are expressed as the mean \pm standard deviation (\% cell viability) of triplicate experiments. ${ }^{*} \mathrm{P}<0.01$ vs. prednisolone. DKK1, Dickkopf-related protein 1.

became sensitive to anticancer drugs, including VCR, VDS, doxorubicin and etoposide, following DKK1-CM treatment, as was revealed by their respective $\mathrm{IC}_{50}$ concentrations.

To quantify the status of apoptosis in these cells, they were analyzed by flow cytometry. The results showed that the proportion of apoptotic cells was increased significantly following the DKK1-CM treatment (Fig. 2B and C).

Wnt/ $\beta$-catenin signaling of relapsed ALL cells is over-activated with improved chemo-sensitivity. A total of four matched pairs of primary bone marrow samples were collected from patients at the initial diagnosis of ALL and relapsed ALL to evaluate activation of the Wnt $/ \beta$-catenin pathway. Expressions of nuclear $\beta$-catenin and LEF1 were observed in samples from newly diagnosed patients with ALL and relapsed patients with ALL. In addition, three of four samples from newly diagnosed patients exhibited a significant decrease in expressions of nuclear $\beta$-catenin and LEF1, whereas all relapsed samples exhibited increased expressions of nuclear $\beta$-catenin and LEF1 (Fig. 3).

To investigate whether Wnt inhibition sensitizes relapsed leukemic cells to anticancer drugs, changes in chemo-sensitivity to prednisolone in leukemic blasts from three relapsed samples were examined following DKK1-CM treatment. Prednisolone was chosen because a previous study demonstrated that relapsed ALL blasts exhibited strong resistance to glucocorticoids (12). As expected, all relapsed samples exhibited increased chemo-sensitivity in response to Wnt inhibition (Fig. 4).

MDR I/P-gp protein and MRP expressions. Overexpression of P-gp (MDR-1), which acts as a drug efflux pump to decrease the intracellular accumulation of anticancer drugs, is one of the major mechanisms underlying drug resistance. Drug resistance may be also attributed to the overexpression of proteins in the MRP family, which is a member of the ABC transporter superfamily. In this study, the expression of MDR1/P-gp and 


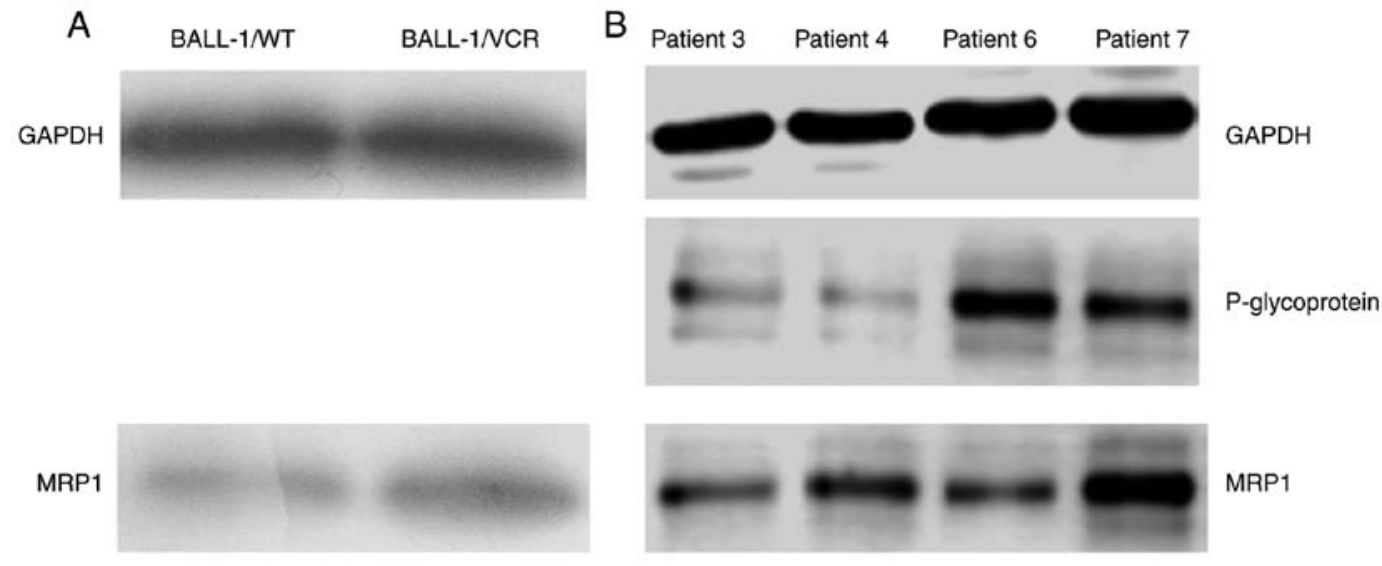

Figure 5. (A) Expression levels of MRP1 protein in BALL-1/WT and BALL-1/VCR. (B) Expression levels of P-glycoprotein and MRP1 protein in blast cells derived from two newly diagnosed patients (patient 3 and 4) and two relapsed patients (patient 6 and 7) determined by western blot analysis. MRP1, multidrug resistance-associated protein.

MRP1 in the cells was determined using western blot analysis. The expression of P-gp was undetectable in both BALL-1/WT and BALL-1/VCR cells, whereas the expression of MRP1 was increased in BALL-1/VCR cells compared with WT (Fig. 5A). Notably, in the blasts from two relapsed ALL samples, the expression of P-gp and MRP1 was significantly increased compared with the blasts from newly diagnosed ALL samples (Fig. 5B).

Therefore, the development of drug resistance in BALL-1/VCR cells may be primarily attributed to the overexpression of MRP1 rather than MDR1/P-gp. In addition, the development of drug resistance in relapsed ALL may be associated with the overexpression of MRP1 and MDR1/P-gp.

\section{Discussion}

Despite generally favorable outcomes of childhood ALL, relapse still occurs with a dismal prognosis, thus it is important to develop novel therapeutic modalities. Drug resistance and early disease recurrence lead to limited survival of patients with ALL (13). Previous attempts to overcome drug resistance by increasing the dose of chemotherapeutic agents have resulted in severe side effects and even death. Therefore, new therapeutic modalities were employed to suppress relevant signaling pathways and overcome drug resistance.

In activation of the Wnt pathway, Wnt proteins bind to cell surface receptors and induce a complex signaling cascade to regulate cell growth and differentiation during hematopoiesis (14). Considering that hematological malignancies arise from immature hematopoietic stem cells, one or more Wnt genes are often overexpressed and functionally important in hematological malignancies $(7,15)$. Increasing evidence has indicated that the $\mathrm{Wnt} / \beta$-catenin pathway has a role in leukemia (16). For example, the Wnt/ $\beta$-catenin pathway is required for the development of leukemia stem cells in AML (17). In addition, inhibition of the Wnt/ $\beta$-catenin signaling pathway leads to collateral chemo-sensitivity in multidrug-resistant ALL cells (18), whereas aberrations of the Wnt/ $\beta$-catenin pathway induce cell death in B-cell ALL cell lines (19). Hu et al (20) reported that Galectin-3 mediates drug resistance in acute leukemia cells via the $\mathrm{Wnt} / \beta$-catenin signaling pathway.
In the current study, a drug-resistant variant of the human ALL cell line BALL-1 (BALL-1/VCR) that had relatively specific resistance to both doxorubicin and etoposide was used. Furthermore, the role of Wnt family members and their downstream signaling components in BALL-1/VCR cells was evaluated. Nuclear $\beta$-catenin and LEF1 (one of the downstream targets of the Wnt pathway) were selected as markers of $\mathrm{Wnt} / \beta$-catenin pathway activation. Over-activation of the Wnt/ $\beta$-catenin signaling pathway was observed in BALL-1/VCR and was identified as a potential mechanism underlying ALL recurrence, consistent with the results obtained in a previous study (12). The importance of the Wnt/ $\beta$-catenin pathway in leukemogenesis has been reported previously $(12,21,22)$. For example, Dandekar et al (12) revealed that over-activation of the Wnt signaling pathway may contribute to the chemo-resistance in relapsed childhood ALL. Furthermore, treatment by two small-molecule inhibitors of the Wnt/ $\beta$-catenin signaling pathway induced apoptosis of CLL cells in vitro and in vivo (22). In addition, the inhibition of the Wnt/ $\beta$-catenin signaling pathway, which sensitizes the resistant cells to chemotherapy, appears to be an attractive strategy to maximize the chemotherapeutic potency of ALL.

During Wnt activation, Wnt proteins bind to cell surface receptors encoded by the Fzd family, which allows $\beta$-catenin to accumulate and to enter the nucleus so that it can interact with TCF1 and LEF1 to recruit other proteins, thus promoting the activation of Wnt target genes, leading to cell proliferation and survival (23). Once Wnt binds to its cell-surface receptor, which consists of Fzd, and LRP5 and 6, it becomes essential for stabilization of $\beta$-catenin. In the current study, the mRNA expression of Wnt3, Wnt5b, Wnt10a, Wnt14, Wnt16, Fzd3, Fzd6, LRP5 and LRP6 was significantly upregulated in BALL-1/VCR cells compared with wild-type BALL-1, while three of the nine Wnt genes, Wnt 3a, Wnt16 and LRP5, were significantly overexpressed in BALL-1/VCR.

Activation of the Wnt signaling pathway has been broadly implicated in tumor formation, in which the transcriptional repression of TCF1 has an important role (24). It has previously been demonstrated that TCF1-knockout mice are prone to develop intestinal tumors and highly metastatic thymic lymphoma $(25,26)$. Wnt3a, which has been confirmed as an 
agonist of the Wnt $/ \beta$-catenin signaling pathway, promotes the proliferation of mouse pro-B cells in bone marrow by initiating a series of signaling events, eventually leading to the $\beta$-catenin-dependent activation of the LEF1 transcription factor. The overexpression of LEF-1 is strongly associated with tumorigenesis of B-cell chronic lymphocytic leukemia (27) and predicts unfavorable outcomes of patients with B-precursor ALL (28). The presence of a complete Wnt/Fzd/LRP/LEF1 gene expression signature in the BALL-1/VCR cells suggests the functional importance of the canonical Wnt signaling pathway. Therefore, the overexpression of Wnt family members, nuclear $\beta$-catenin and LEF1, indicates over-activation of the Wnt signaling pathway in BALL-1/VCR cells and the blasts from relapsed ALL.

In this study, DKK1, a Wnt antagonist (29), was used to treat BALL-1/VCR cells and inhibit the effect of Wnt/ $\beta$-catenin signaling in these cells, thus leading to an increased level of chemo-resistance. Activation of the Wnt/ $\beta$-catenin pathway can be competitively blocked with a secreted form of Wnt antagonist, DKK1 (30). There are two possible mechanisms by which DKK1 inhibits the Wnt signaling pathway: One is that DKK1 prevents the formation of Fz-LRP6 complex, which is necessary for activation of the Wnt/ $\beta$-catenin pathway; the other is that DKK1 interacts with the LRP/Kremen co-receptor complex and induces the internalization of Wnt proteins, thus attenuating intensity of the Wnt signaling pathway.

The resistance of cancer cell lines is associated with multiple mechanisms, each of which has its own distinct features. The multidrug resistance of classical MDR cell lines is associated with reduced drug accumulation and the overexpression of MDR1/P-gp, a membrane protein that functions as a drug efflux pump. Although the susceptibility to VCR in BALL-1/VCR cells was 20 -fold lower than that in wild-type BALL-1/WT cells, there was no detectable expression of MDR1 mRNA or $\mathrm{P}$-gp in either cell lines. Thus, P-gp is apparently not involved in the development of drug resistance in BALL-1/VCR cells. Several cell lines, including a mitoxantrone-resistant MCF7 cell line (31) and a VP16-resistant MCF7 cell line (32), have been demonstrated to exhibit an apparent defect in drug accumulation when the expression of MDR1/P-gp is absent.

Several studies have demonstrated the overexpression of MRP protein, which shares the homology with several members of the ABC superfamily and is therefore thought to be involved in multidrug resistance, in resistant cell lines $(4,31,33)$. When the expression of MRP in BALL-1/VCR and BALL-1 cells was compared, it was observed that MRP expression was increased in resistant cells. Therefore, it is possible that MRP overexpression is involved in the development of the multidrug resistance phenotype in BALL-1/VCR cells.

Clinical studies have also reported that the overexpression of MDR-1 and MRP may contribute to the development of cross-resistance to multiple anticancer agents $(3,33)$. Similarly, the overexpression of MRP was observed in BALL-1/VCR cells and blasts isolated from relapsed ALL samples, whereas the overexpression of P-glycoprotein was not observed. Therefore, the molecular mechanism underlying the drug-resistance of relapsed ALL may attributed to the increased expression of ABC transporters, including MDR-1 and MRP proteins. However, ALL relapse not only depends on chemotherapy resistance, but may also originate from either major or minor clones present at the time of diagnosis (34). Nevertheless, the overexpression of MDR-1 and MRP may be involved in leukemia relapse.

In conclusion, the current study produced a novel BALL-1 variant cell line that was specifically resistant to VCR. The expression of components in the Wnt signaling pathway of BALL-1/VCR cells and blasts isolated from relapsed ALL samples suggested an important role of the Wnt signaling pathway in ALL relapse. Selective suppression of the Wnt signaling pathway using DKK1 sensitized BALL-1/VCR cells anticancer agents. In addition, the chemo-sensitivity to prednisolone in blasts from relapsed ALL was restored by Wnt inhibition. As the resistance in BALL-1/VCR cells is potentially attributed to the overexpression of MRP, drug resistance in relapsed ALL may be associated with the overexpression of MRP1 and MDR1/P-gp. Therefore, disruption of the Wnt signaling pathway may have be of use for ALL treatment, while targeting the Wnt signaling pathway with a more specific pharmacologic antagonist, including antibodies and cytotoxins, is an attractive therapeutic strategy for relapsed ALL.

\section{Acknowledgements}

The authors are appreciative to Professor Dao-xin Ma (Department of Hematology, Qilu Hospital, Shandong University, Jinan, China) and Institute of Immunology, Shandong University (Jinan, China) for the cell line donation.

\section{Funding}

This work was supported by Scientific Research Fund Project of Shandong University Qilu Hospital (grant nos. 2016QLQN18 and 2017QLQN19), Natural science fund of Shandong Province (grant nos. ZR2014HM060, ZR2014HM093 and ZR2014HP037, ZR2017BH111) and Shandong Province Key R\&D Fund (grant no. 2017GSF218015).

\section{Availability of data and materials}

The datasets used and/or analyzed during the current study are available from the corresponding author on reasonable request.

\section{Authors' contributions}

JF conceptualized and designed the study, and drafted the initial manuscript. LS carried out the study, reviewed and revised the manuscript. YZ collected the samples, analyzed the data and revised the manuscript. AZ collected the samples, analyzed the data and revised the manuscript. NS collected the samples, analyzed the data and revised the manuscript. DL coordinated and supervised the data collection, and critically reviewed the manuscript. BH analyzed the data and revised the manuscript. XJ designed the data collection instruments, coordinated and supervised the data collection, and critically reviewed the manuscript. All authors read and approved the final manuscript.

\section{Ethics approval and consent to participate}

Informed consent was obtained from all patients or their guardians. The protocol followed the Declaration of Helsinki 
and was approved by Ethic Committee in Qilu Hospital of Shandong University (no. KYLL-2017-253).

\section{Patient consent for publication}

Informed consent was obtained from all patients or their guardians.

\section{Competing interests}

The authors declare that they have no competing interests.

\section{References}

1. Leonardi DB, Abbate M, Riccheri MC, Nuñez M, Alfonso G, Gueron G, De Siervi A, Vazquez E and Cotignola J: Improving risk stratification of patients with childhood acute lymphoblastic leukemia: Glutathione-S-Transferases polymorphisms are associated with increased risk of relapse. Oncotarget 8: 110-117, 2017.

2. Jaime-Perez JC, Pinzon-Uresti MA, Jimènez-Castillo RA, Colunga-Pedraza JE, González-Llano Ó and Gómez-Almaguer D: Relapse of childhood acute lymphoblastic leukemia and outcomes at a reference center in Latin America: Organomegaly at diagnosis is a significant clinical predictor. Hematology 23: $1-9,2018$.

3. Mahjoubi F and Akbari S: Multidrug resistance-associated protein 1 predicts relapse in Iranian childhood acute lymphoblastic leukemia. Asian Pac J Cancer Prev 13: 2285-2289, 2012.

4. Zareifar S, Monabati A, Saeed A, Fakhraee F and Cohan N: The association of glutathione S-transferase gene mutations (including GSTT1 and GSTM1) with the prognostic factors and relapse in acute lymphoblastic leukemia. Pediatr Hematol Oncol 30: 568-573, 2013.

5. Hunyadi A, Csábi J, Martins A, Molnar J, Balázs A and Tóth G: Backstabbing P-gp: Side-chain cleaved ecdysteroid 2,3-dioxolanes hyper-sensitize MDR cancer cells to doxorubicin without efflux inhibition. Molecules 22: pii: E199, 2017.

6. Cai J, Fang L, Huang Y, Li R, Xu X, Hu Z, Zhang L, Yang Y, Zhu X, Zhang H, et al: Simultaneous overactivation of Wnt/ $\beta$-catenin and TGF $\beta$ signalling by miR-128-3p confers chemoresistance-associated metastasis in NSCLC. Nat Commun 8: 15870, 2017.

7. Ashihara E, Takada T and Maekawa T: Targeting the canonical $\mathrm{Wnt} / \beta$-catenin pathway in hematological malignancies. Cancer Sci 106: 665-671, 2015

8. Lu C, Cui C, Liu B, Zou S, Song H, Tian H, Zhao J and Li Y: FERMT3 contributes to glioblastoma cell proliferation and chemoresistance to temozolomide through integrin mediated Wnt signaling. Neurosci Lett 657: 77-83, 2017.

9. Ma LS, Jiang CY, Cui M, Lu R, Liu SS, Zheng BB, Li L and Li X: Fluopsin $\mathrm{C}$ induces oncosis of human breast adenocarcinoma cells. Acta Pharmacol Sin 34: 1093-1100, 2013.

10. Livak KJ and Schmittgen TD: Analysis of relative gene expression data using real-time quantitative PCR and the 2(-Delta Delta C(T)) method. Methods 25: 402-408, 2001.

11. Si L, Tian H, Yue W, Li L, Li S, Gao C and Qi L: Potential use of microRNA-200c as a prognostic marker in non-small cell lung cancer. Oncol Lett 14: 4325-4330, 2017.

12. Dandekar S, Romanos-Sirakis E, Pais F, Bhatla T, Jones C, Bourgeois W, Hunger SP, Raetz EA, Hermiston ML, Dasgupta R, et al: Wnt inhibition leads to improved chemosensitivity in paediatric acute lymphoblastic leukaemia. Br J Haematol 167: 87-99, 2014.

13. Scheijen B, Boer JM, Marke R, Tijchon E, van Ingen Schenau D, Waanders E, van Emst L, van der Meer LT, Pieters R, Escherich G, et al: Tumor suppressors BTG1 and IKZF1 cooperate during mouse leukemia development and increase relapse risk in B-cell precursor acute lymphoblastic leukemia patients. Haematologica 102: 541-551, 2017.

14. Luis TC, Ichii M, Brugman MH, Kincade P and Staal FJ: Wnt signaling strength regulates normal hematopoiesis and its deregulation is involved in leukemia development. Leukemia 26: 414-421, 2012.

15. Ge X and Wang X: Role of Wnt canonical pathway in hematological malignancies. J Hematol Oncol 3: 33, 2010.
16. Undi RB, Gutti U, Sahu I, Sarvothaman S, Pasupuleti SR, Kandi R and Gutti RK: Wnt signaling: Role in regulation of haematopoiesis. Indian J Hematol Blood Transfus 32: 123-134, 2016.

17. Yang Y, Mallampati S, Sun B, Zhang J, Kim SB, Lee JS, Gong Y, Cai $Z$ and Sun $X$ : Wnt pathway contributes to the protection by bone marrow stromal cells of acute lymphoblastic leukemia cells and is a potential therapeutic target. Cancer Lett 333: 9-17, 2013.

18. Hamdoun S, Fleischer E, Klinger A and Efferth T: Lawsone derivatives target the $\mathrm{Wnt} / \beta$-catenin signaling pathway in multidrug-resistant acute lymphoblastic leukemia cells. Biochem Pharmacol 146: 63-73, 2017.

19. Saba NS, Angelova M, Lobelle-Rich PA and Levy LS: Disruption of pre-B-cell receptor signaling jams the $\mathrm{WNT} / \beta$-catenin pathway and induces cell death in B-cell acute lymphoblastic leukemia cell lines. Leuk Res: Aug 10, 2015 (Epub ahead of print). doi: 10.1016/j.leukres.2015.08.002.

20. Hu K, Gu Y, Lou L, Liu L, Hu Y, Wang B, Luo Y, Shi J, Yu X and Huang H: Galectin-3 mediates bone marrow microenvironment-induced drug resistance in acute leukemia cells via Wnt/ $\beta$-catenin signaling pathway. J Hematol Oncol 8: 1, 2015.

21. Seke Etet PF, Vecchio L and Nwabo Kamdje AH: Interactions between bone marrow stromal microenvironment and B-chronic lymphocytic leukemia cells: Any role for Notch, Wnt and $\mathrm{Hh}$ signaling pathways? Cell Signal 24: 1433-1443, 2012.

22. Gandhirajan RK, Staib PA, Minke K, Gehrke I, Plickert G, Schlösser A, Schmitt EK, Hallek M and Kreuzer KA: Small molecule inhibitors of Wnt/beta-catenin/lef-1 signaling induces apoptosis in chronic lymphocytic leukemia cells in vitro and in vivo. Neoplasia 12: 326-335, 2010.

23. Bejsovec A: Wnt pathway activation: New relations and locations. Cell 120: 11-14, 2005.

24. Drager J, Simon-Keller K, Pukrop T, Klemm F, Wilting J, Sticht C, Dittmann K, Schulz M, Leuschner I, Marx A and Hahn H: LEF1 reduces tumor progression and induces myodifferentiation in a subset of rhabdomyosarcoma. Oncotarget 8: 3259-3273, 2017.

25. Yu S, Zhou X, Steinke FC, Liu C, Chen SC, Zagorodna O, Jing X, Yokota Y, Meyerholz DK, Mullighan CG, et al: The TCF-1 and LEF-1 transcription factors have cooperative and opposing roles in T cell development and malignancy. Immunity 37: 813-826, 2012.

26. Tiemessen MM, Baert MR, Schonewille T, Brugman MH, Famili F, Salvatori DC, Meijerink JP, Ozbek U, Clevers H, van Dongen JJ and Staal FJ: The nuclear effector of Wnt-signaling, Tcf1, functions as a T-cell-specific tumor suppressor for development of lymphomas. PLoS Biol 10: e1001430, 2012.

27. Gutierrez A Jr, Tschumper RC, Wu X, Shanafelt TD, Eckel-Passow J, Huddleston PM III, Slager SL, Kay NE and Jelinek DF: LEF-1 is a prosurvival factor in chronic lymphocytic leukemia and is expressed in the preleukemic state of monoclonal B-cell lymphocytosis. Blood 116: 2975-2983, 2010.

28. Kuhnl A, Gökbuget N, Kaiser M, Schlee C, Stroux A, Burmeister T, Mochmann LH, Hoelzer D, Hofmann WK, Thiel E and Baldus CD: Overexpression of LEF1 predicts unfavorable outcome in adult patients with B-precursor acute lymphoblastic leukemia. Blood 118: 6362-6367, 2011.

29. Mao B, Wu W, Davidson G, Marhold J, Li M, Mechler BM, Delius H, Hoppe D, Stannek P, Walter C, et al: Kremen proteins are Dickkopf receptors that regulate Wnt/beta-catenin signalling. Nature 417: 664-667, 2002.

30. Yamamoto H, Sakane H, Yamamoto H, Michiue T and Kikuchi A: Wnt3a and Dkk1 regulate distinct internalization pathways of LRP6 to tune the activation of beta-catenin signaling. Dev Cell 15: 37-48, 2008.

31. Morrow CS, Peklak-Scott C, Bishwokarma B, Kute TE, Smitherman PK and Townsend AJ: Multidrug resistance protein 1 (MRP1, ABCC1) mediates resistance to mitoxantrone via glutathione-dependent drug efflux. Mol Pharmacol 69: 1499-1505, 2006.

32. Sehested M, Friche E, Jensen PB and Demant EJ: Relationship of VP-16 to the classical multidrug resistance phenotype. Cancer Res 52: 2874-2879, 1992.

33. Chen GK, Duran GE, Mangili A, Beketic-Oreskovic L and Sikic BI: MDR 1 activation is the predominant resistance mechanism selected by vinblastine in MES-SA cells. $\mathrm{Br}$ J Cancer 83: 892-898, 2000.

34. SunC,ChangLandZhuX:Pathogenesis ofETV6/RUNX1-positive childhood acute lymphoblastic leukemia and mechanisms underlying its relapse. Oncotarget 8: 35445-35459, 2017. 